\title{
Analysis of Enterprise Environment Cost Management under Perspective of Low Carbon Economy
}

\author{
Jing Zhang \\ Department of International Economics and Trade, Xi'an International University, Xi'an, 710077, \\ China
}

Keywords: low carbon economy; enterprise; environment cost management

\begin{abstract}
Under current new economic environment, enterprises should conform to national policies and regulations and strive to adapt economic development tide. So, enterprise environment cost management under the perspective of low carbon economy must be enhanced in order to better reduce cost, gain maximization of income and achieve better and faster development. This paper summarizes environment of low carbon economy, discusses the necessity of enterprise environment cost management under the perspective of low carbon economy and proposes corresponding countermeasures.
\end{abstract}

\section{Introduction}

In recent years, global natural environment has continuously deteriorated. Low carbon economy as one of economic development mode which can achieve win-win of ecological environmental protection and economic and society development is deeply valued. Thus, various countries in the world universally feel this can well solve global warming issue. Enterprise cost management always aims at economic field, while the contents oriented to natural resources and environmental system are few. However, continuously deteriorative environment results in great constraints of human health. In view of this, it is very urgent to list environment cost management in enterprise cost management under low carbon environment.

\section{Overview of low carbon economic environment}

Low carbon economy mainly refers to an economic development mode based on low energy consumption, low pollution and low emission. Its purpose is to reduce emission of carbon dioxide and other greenhouse gases so as to better develop circular economy and green economy, further improve resource use ratio, make a resource-saving and environment-friendly industrial development rode, apply the lowest cost to gain maximization of income and reduce post-governance cost. Natural resource is an important condition for maintaining human survival and development. Enterprises should gain resources from nature to bring new income for enterprises. So, enterprises must return to nature and more actively undertake the reputability for the society based on resources and environment so as to better improve enterprise operation environment. As economic environment continues to change, business goal transforms to stakeholders' value maximization. Thus, only when stakeholders' value maximization is achieved can enterprise value maximization be further realized. Thus, enterprises should actively develop low carbon economy and combine economic development and environmental protection to attract numerous consumers and investors.

\section{Necessity of enterprise environment cost management under perspective of low carbon economy}

Firstly, it can effectively control environmental risk. Enterprise environment behaviors are often restricted by social responsibility. In recent years, national implementation force for environmental protection laws and policies has become increasingly large so that constraining force for enterprises becomes stronger and stronger. In such case, once enterprises continuously discharge carbon 
dioxide and other harmful pollutants in the production process and the emission load exceeds national and local standards or the emission leads to huge damages to surrounding ecological system and human health, the enterprises will be faced with fine, lawsuit or compensatory governance of pollution. This leads to great losses for enterprises. Once pollution becomes serious, enterprises will have to be closed.

Secondly, it can effectively help enterprise management level make correct decisions. When enterprise managers make investment decisions, environment cost must be considered, because environment cost input is closely related to enterprise profit. Enterprise profit is affected by realization of environmental standards. Therefore, it is required to manage environment cost in a scientific and standard way, which will provide good support for coordinating environmental protection and enterprise development and make scientific decisions.

Thirdly, it can effectively reduce enterprise environment cost. The idea of product life cycle and activity-based costing should be jointly introduced in management of enterprise environment cost so as to correctly analyze causes of environment cost and apply rational enterprise environment cost management methods to reduce environment cost.

Fourthly, it can effectively perfect and improve modern enterprise system. Enterprises will generally neglect social benefit and pursue their own development. Currently, modern enterprise system requires enterprises transforming to operation type from production type. This requires coordinating social development demand and their benefits. Rational environment cost management can not just reduce enterprises' resource consumption and decrease environment pollution, but also deeply explore environment problems and lower cost. So, enterprises can promote enterprises' economic benefit and enhance competitive strength of products. Meanwhile, environmental protection and efficient utilization of resources should be combined to promote comprehensive and harmonious sustainable development of economic society.

Fifthly, it can carry out effective performance assessment of enterprise environment. As current environmental issue stands out, Chinese laws and regulations in environmental protection and policies are improved continuously. Enterprises' environmental protection becomes increasingly large. So, giving full play to high efficiency features of environment cost can reduce environmental protection cost expenditure and increase more benefits for enterprises. At present, enterprises receive more and more attention. Controlling environment cost management contributes to evaluating enterprises' environmental protection performance so as to fulfill requirements of environmental performance assessment.

\section{Countermeasures of enterprise environment cost management under perspective of low carbon economy}

\section{(I) To enhance environmental risk responsibility sense of enterprise management level}

Since Chinese environment continues to deteriorate, relevant national organs increasingly value environmental problems. Since the reform and opening-up, China has worked out and issued many laws and regulations involving environmental pollution, resources and sustainable development, specified environmental protection is one of Chinese basic state policies, proposed the policy of promoting unity of economic benefit, social benefit and environmental benefit and implemented the policies of prevention first and combination of prevention and governance. In recent years, China implemented sustainable development strategy, actively developed low carbon economy and improved national energy conservation and environmental protection consciousness. Of course, enterprise environment behaviors will be increasingly constrained. Environmental risks continuously increase, while low carbon economy puts forward new environmental protection requirements for enterprises. Enterprises should generate the lowest production in the production process. Besides, it is necessary to actively reduce impact force of products for environment in life cycle and strive to achieve the minimization. Only when enterprises strengthen environmental responsibility awareness and environmental risk awareness can they develop into one of important enterprise cultures. In this way, enterprise development can speed up and economic benefit and social benefit can achieve. 


\section{(II) To carry out theoretical research on environment accounting to formulate feasible environment accounting mechanism}

Under the perspective of low carbon economy, it is badly necessary to reestablish international accounting mechanism of environment cost. This requires environment exploration and study of cost theory and methods under low carbon economic development environment and actively perfecting environment cost accounting system. As economic situation continuously changes, a large number of problems of enterprise environment cost accounting control need to be solved, such as cost measurement of carbon emission, emission load measurement and environment cost report. The government should start from children and make various activities approach nature under the new situation of actively advocating environmental awareness globally so as to understand the necessity of harmonious coexistence between human and nature. Because China's energy conservation and emission reduction is faced with huge pressure, the government needs to formulate and perfect relevant accounting norms and rules as far as possible. The government should strive to increase punishment of enterprises leading to pollution and combine state-owned enterprises with taxes paid and performance evaluation so as to compulsively disclose environment information. Besides, it is required to gradually implement internationally approved ISO14000 quality authentication standards and enhance environment supervision from production link to product recycle.

\section{(III) To introduce product life cycle (PLC) evaluation method to control environment cost}

PLC evaluation method mainly means PLC is divided into product design, raw material exploitation, production, consumption and waste recovery, and environmental impacts in the whole process from raw material exploitation, termination of using finished products to discharge to earth are evaluated. It is required to start from PLC, analyze environmental pollution in multiple stages such as product design, material purchase, production and sales and apply different types of prevention control methods. When the product is designed, it is required to establish environment cost control awareness, further combine low-carbon and environmentally-friendly materials to carry out cleaner production and green marketing so as to fundamentally control environment expenditure and effectively prevent corresponding environment cost. In addition, it is required to carry out beforehand planning, in-process supervision and post-action control for environment cost, reduce environment cost on the basis of internal and external surroundings and PLC process, and then realize win-win of environmental benefit and economic benefit. This evaluation method should not just be static evaluation, but long-term and repeated dynamic evaluation. This evaluation will continuously develop with understanding of activities. The effects of improving environmental influence based on evaluation method may be gradually incremental. This is because every evaluation is set based on the last step. This means PLC evaluation is not one-off treatment implemented to cure all environmental diseases.

Firstly, implement beforehand planning control. Practice experience of many enterprises proves that once environmental policy works, it will not just influence investment policy, but also play a part in R\&D process, finished products and process design. In the stage of product design and development, environmental problems related to products should be considered to practically fuse environmental protection, health and safety awareness in design scheme. To be more specific, continuously increasing environmental requirements may obviously increase product cost, while product cost has been established during the design. It thus can be seen that beforehand planning control aims to comprehensively evaluate environment cost of the product, list it into the budget and then carry out economic evaluation and feasibility assessment of product design scheme with cost-benefit analysis and then gain the ideal design scheme and control environment cost from the root.

Secondly, implement in-process control. To really implement design scheme of environment-friendly products, relevant raw materials should be purchased rationally. Unreasonable raw material purchase will increase transport package, material storage and custody fees. So, effects of each detail in the procurement link on environment should be taken into account to lower environment cost to the largest extent. In the opinion of the author, cleaner production is a very 
effective method. It mainly refers to application of comprehensive prevention strategy in production process and products so as to reduce risks caused to human and environment as far as possible. The implementation of cleaner production is based on PLC. This represents improvement of utilization ratio of raw materials and energy. Non-poisonous and harmless materials should be used to comprehensively control the quantity of wastes and toxicity before producing and emitting wastes, which can achieve minimization of wastes discharge and even directly wastes in production process.

Thirdly, implement post-action control. In the even of environmental pollution, enterprises must take timely measures to eliminate impacts on environment to establish favorable environmental protection image and keep good reputation of products in the market. Such post-action control mainly means an enterprise tries to make up after causing environmental pollution. Current financial accounting lists various expenses incurred in this process in environment cost. Actually, it is had to avoid environmental pollution in current production and management. So, post-action control becomes a very important means for cost control. Enterprises should look at the overall situation and organically connect beforehand planning, in-process supervision and post-action control so as to achieve optimization of economic benefit and environmental benefit.

(IV) To establish hand perfect relevant laws and regulations and fuse reward and punishment mechanism in environment cost

It is required to continuously perfect environmental protection law and regulation system under low carbon economy, comprehensively combine environmental protection laws and regulations as well as environmental standards. It is required to continuously control emission limit value acceding to the requirement of environmental quality. Meanwhile, it is required to establish hand perfect relevant incentive policies and overall encourage enterprises to independently implement environment cost accounting and control. For example, environment cost control and accounting should be actively implemented. Relative privilege should be given to enterprises for investment projects in environmental protection in interest rate, repayment mode and loan limit. Tax revenue privilege should be given to $R \& D$ enterprises and use enterprises of environmental equipment so as to reduce import revenue of environmental protection products. For low-carbon production enterprises, technical support should be provided so that enterprises can more effectively control environment cost.

\section{Conclusions}

To sum up, enterprise environment cost management is a very complex system project. Enterprises must always stock to win-win principle. Enterprises should neither pursue economic benefit at the cost of sacrificing environment nor give up long-term development for environment protection. It is required to spare no effort to coordinate relationship between enterprise development and environmental protection, enhance enterprise environment cost management so as to control expenditure caused by environmental damage, effectively reduce environment risk and promote sustainable development.

\section{Acknowledgments}

This paper is social scientific planning fund program of Xi'an in 2014, with the title of current situation of Xi'an carbon emission and development strategy of low carbon economy; project number: $14 \mathrm{IN} 16$

\section{References}

[1] Xu Jialin, Environment Accounting: development and innovation of theory and practice [J]. Accounting Research, 2009 (10)

[2] Li Fubin, He Hua, Effects of low carbon economy on enterprise environment cost control [J]. Chinese Certified Public Accountant, 2011 (2) 
[3] Ma Huiying, New thought of environment cost study under low-carbon economic background [J]. Research of Finance and Accounting, 2013 (3)

[4] Li Meqin, Study on china's enterprise environment cost control system under low carbon economy [J]. Green Finance and Accounting, 2013 (6)

[5] Gao Yi, Analysis of enterprise environment cost accounting under low carbon economy [J]. Chinese and Foreign Entrepreneurs, 2014 (8) 